\title{
Experimental study of rock-breaking with an offset single cone bit*
}

\author{
Chen Yinghua $* *$
}

School of Mechanical and Electronic Engineering, China University of Petroleum, Beijing 102249, China

\begin{abstract}
An experimental study of rock-breaking with an offset single cone bit was completed on the bit bench test equipment. Data such as transmission ratio, weight on bit (WOB), rate of penetration (ROP) and torque on bit were acquired in the experiments. Based on analyzing the experimental results, several conclusions were drawn as follows. The transmission ratio of the offset single-cone bit changed slightly with rotary speed of bit, weight on bit and offset distance. The rate of penetration of the offset singlecone bit increased with increase of WOB and offset distance. The torque on bit increased with increase of offset distance under the same WOB and bit rotary speed, decreased with increase of bit rotary speed under the same WOB. The rock-breaking mechanism of the offset single-cone bit was a scraping action. This indicates that the offset single-cone bit is a chipping type bit.
\end{abstract}

Key words: Offset single-cone bit, transmission ratio, rate of penetration, torque on bit

\section{Introduction}

In order to accelerate the exploration and development of China's oil and gas resources, especially the deep offshore reservoirs and complex reservoirs, it is necessary to develop new drilling technology and equipment. Since the 1990s, the slim hole drilling technology is the focus of research for new drilling technology, the development of a new type of bit is the key to slim hole drilling technology (Fletcher, 2003; Langford Jr, 1999; Li and Tan, 2000; Qiu, 2000; Wu and Liu, 2000; Yu et al, 1994).

Compared with conventional single-cone bit (with no offset), the offset single-cone bit has new structural characteristics, providing more selections of bit types for modern slim hole drilling (Deng et al, 2001; Ma et al, 2004; Moran and Witman, 2004; Witman et al, 2006; Xia et al, 2002; Yu and $\mathrm{Yu}, 2007)$. However, the rock-breaking mechanism and drilling characteristics of the offset singlecone bit are still issues to be studied.

The transmission ratio (i.e. the ratio of cone rotary speed to bit rotary speed) is a key parameter for bit design, which is essential to analyzing the trajectory of teeth on the cone. Therefore, it is a vital parameter for the design of cutting structure (Yu et al, 1995). In general, transmission ratio for offset single-cone bit under practical conditions cannot be obtained from theoretical study, so the effect of offset distance on transmission ratio can be obtained only through bench tests.

Compared with conventional single-cone bit, the offset

\footnotetext{
*This work was supported by CNPC Innovation Foundation (No. 03E7020)

**Corresponding author. Email: cyhchenyinghua@163.com

Received August 3, 2007
}

single-cone bit is characterized by an asymmetrical structure, so the rate of penetration (ROP), torque and rock-breaking characteristics must be investigated experimentally through bench tests. At the same time, the bottom hole tracks crushed or cut by offset single-cone bits can also be analyzed.

\section{Experimental apparatus and procedures}

The experiment was performed on bit bench test equipment, developed by Southwest Petroleum University. Fig. 1 shows its schematic diagram. The offset single-cone bit used is shown in Fig. 2.

The bit bench test equipment is composed of a threephase silicon-controlled rectifier control box 1 , direct current electromotor 2 , gear box 3 , lower rotary table 4 , sensors 7 and 8 , joint 9 , measuring joint 10 , hydraulic cylinder 11 , centralizer 12 , upper rotary table 13 , kelly bar 14 , balance beam 15, and a swivel 16 .

During testing, the upper rotary table 13 was locked by pin and was stationary. The lower rotary table 4 , on which the rock 5 was held by a clamping device, was driven by a direct current electromotor 2 through gearing. The rotational speed of the electromotor was adjusted by a three-phase siliconcontrolled rectifier. Then the bit could rotate relative to the rotary table. The hydraulic cylinder 11 could provide the given weight on bit (WOB) and control the vertical movement of bit. Sensors 7 and 8 were installed to monitor rotary speed of the bit and cone.

WOB and torque were measured by resistance strain gauges on the measuring joint, and the linear strain was then converted into voltage signals with dynamic strain gauges.

\section{Analysis of the experimental results}

Four single-cone bits with offset distances, $d$, of $0,3.2,5.8$, 


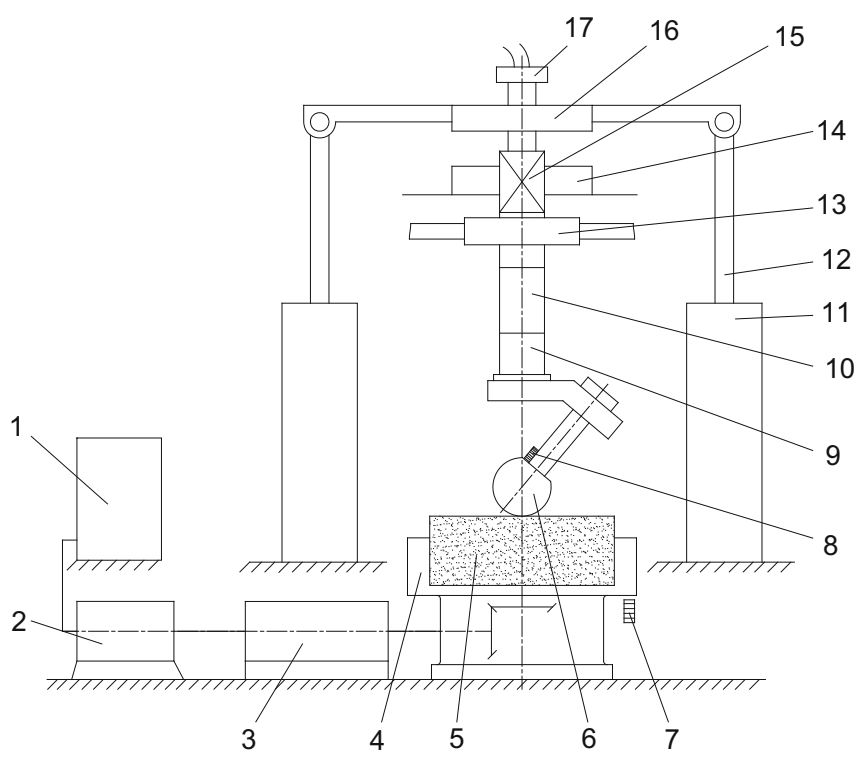

1-Silicon-controlled rectifier control box; 2-Direct current electromotor; 3-Gear box; 4-Lower rotary table; 5-Rock; 6-Single-cone bit; 7, 8-Sensor; 9-Joint; 10-Measuring joint; 11-Hydraulic cylinder; 12-Centralizer; 13-Upper rotary table; 14-Kelly bar; 15-Balance beam; 16-Swivel

Fig. 1 Test bench equipment

$9.0 \mathrm{~mm}$, were tested respectively. The journal angles of these bits used were $40^{\circ}$, and their diameters were $152.4 \mathrm{~mm}$. The rock sample was limestone.

\subsection{Measured signals of WOB, torque on bit and bit rotary speed}

Fig. 3 shows the measured signals of bit torque, WOB and bit rotary speed for the single-cone bit that drilled through the limestone in the laboratory. In these tests, the offset distance of the single-cone bit was $3.2 \mathrm{~mm}$, and the average rotary speed of bit and average applied weight on bit (WOB) were

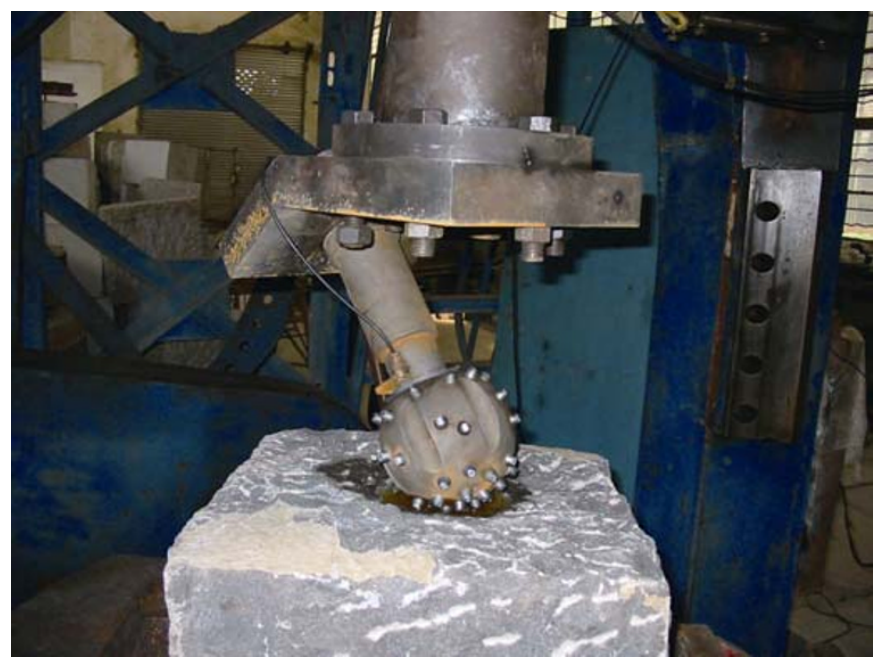

Fig. 2 Offset single-cone bit

$60 \mathrm{rpm}$ and 2 tonnes respectively. As shown in Fig. 3, the actual acquired signal of WOB had similar tendency with that of torque, while the signal of bit rotary speed had reverse tendency with that of torque. This is consistent with the actual situation, and helps indicate that the data acquired in the laboratory were reliable.

\subsection{Transmission ratio}

Data on WOB, torque, rotary speed of bit and rotary speed of cone for the single-cone bits with different offset distances were measured under different experimental conditions. The experimental data and calculated results are shown in Table 1 and 2 .

As shown in Tables 1 and 2, the transmission ratio for single-cone bits with different offset distances changed slightly with the bit rotary speed or WOB. Moreover, for the single-one cone bit, when bit rotary speed and WOB were kept unchanged, the offset distance had a slight influence on transmission ratio.
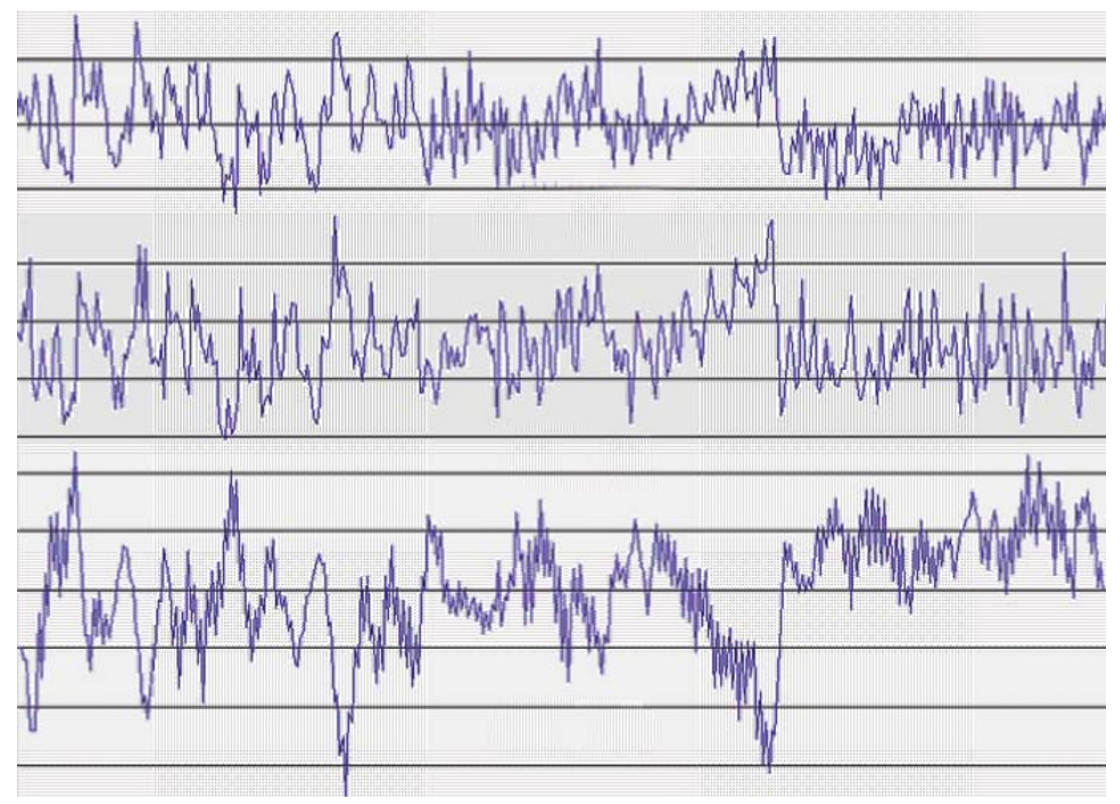

Fig. 3 Electronic signals of WOB, torque on bit and bit rotary speed (a) WOB

(b) Torque

(c) Bit rotary speed increased with WOB, as a result the rock crushed or cut by cone teeth would be increased. WOB. The depth of teeth
of penetration into rock

\subsection{Rate of penetration of the offset single-cone bit}

The rate of penetration (ROP) of single-cone bits with different offset distances were obtained under different WOB values, as shown in Fig. 4, where journal angle $\beta$ was $40^{\circ}$ and bit rotary speed was $60 \mathrm{rpm}$.

Fig. 4 shows that for the offset single-cone bit, ROP increased with increase of 
Table 1 Transmission ratios of single-cone bits at different bit rotary speeds

\begin{tabular}{cccc}
\hline \multirow{2}{*}{$\begin{array}{c}\text { Offset distance } \\
\mathrm{mm}\end{array}$} & \multicolumn{3}{c}{ Transmission ratios at different bit rotary speeds } \\
\cline { 2 - 4 } & $30 \mathrm{rpm}$ & $60 \mathrm{rpm}$ & $90 \mathrm{rpm}$ \\
\hline 3.2 & 0.62 & 0.66 & 0.66 \\
5.8 & 0.59 & 0.65 & 0.60 \\
9.0 & 0.64 & 0.67 & 0.67 \\
\hline
\end{tabular}

Notes: Applied weight on bit was kept at 3 tonnes

Table 2 Transmission ratio of single-cone bits with different offset distances measured at different WOB

\begin{tabular}{cccc}
\hline \multirow{2}{*}{$\begin{array}{c}\text { Offset distance } \\
\mathrm{mm}\end{array}$} & \multicolumn{3}{c}{ Transmission ratios at different WOB } \\
\cline { 2 - 4 } & 2 tonnes & 3 tonnes & 4 tonnes \\
\hline 0 & 0.66 & 0.66 & 0.67 \\
3.2 & 0.65 & 0.65 & 0.62 \\
5.8 & 0.67 & 0.67 & 0.68 \\
9.0 & 0.67 & 0.67 & 0.64 \\
\hline
\end{tabular}

Notes: Rotary speed of bit was $60 \mathrm{rpm}$

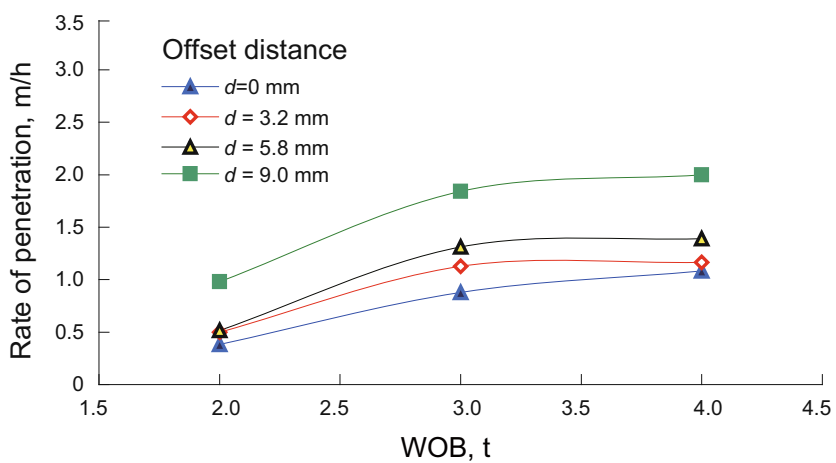

Fig. 4 ROP of the offset single-cone bits when different weights were applied on the bit

For the offset single-cone bit, ROP increased with increase of offset distance when the bit rotated at $60 \mathrm{rpm}$ and the applied WOB was the same. Under the same experimental conditions, rock crushed or cut by teeth decreased with increase of offset distance, therefore the rate of penetration increased.

\subsection{Torque on the single-cone bit}

Fig. 5 shows the torque on single-cone bit under different bit rotary speeds when the WOB was kept at 3 tonnes.

Fig. 6 shows the torque on offset single-cone bit under different WOB when the bit rotary speed was kept at $60 \mathrm{rpm}$.

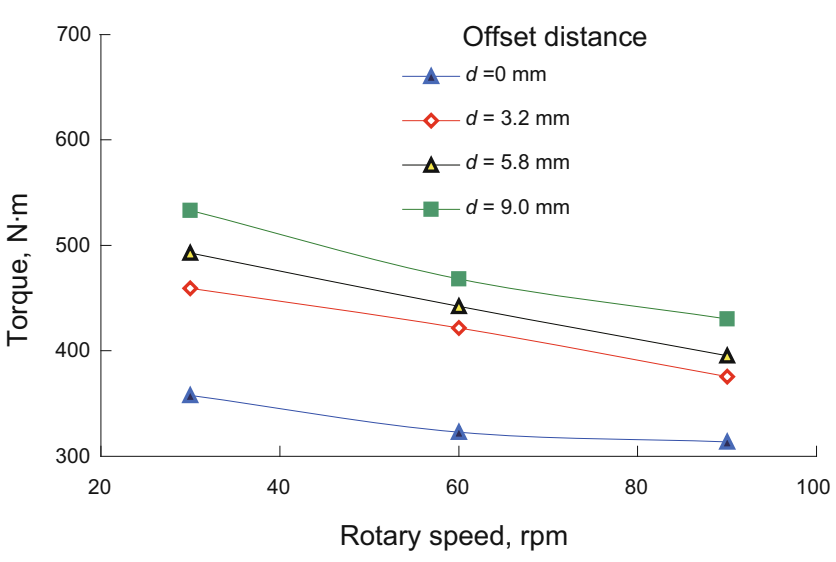

Fig. 5 Torque on offset single-cone bit at different bit rotary speeds

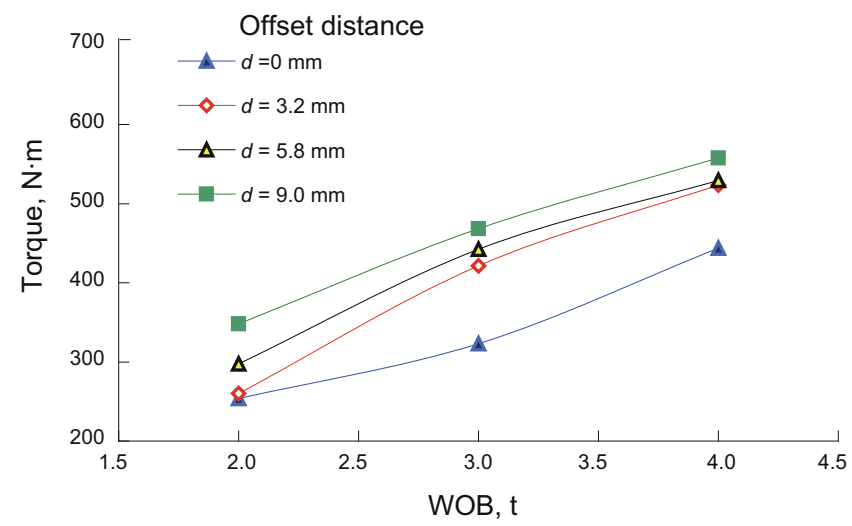

Fig. 6 Torque on offset single-cone bit under different WOB 
The torque on the single-cone bit increased with increase of offset distance under the same experimental conditions. The distance between cone center and bit axis increased with increase of offset distance, as a result the force applied at borehole wall by the cone became larger, and therefore the torque increased.

For the offset single-cone bit, the torque on bit decreased with increasing rotary speed when the applied WOB was the same, this is consistent with the conventional singlecone bit. The torque on bit increased with increasing WOB when the rotary speed of bit was kept unchanged. A possible explanation is that the cutting depth increased with increasing WOB, therefore the torque increased.

\section{Bottom hole track pattern of the offset single-cone bit}

Four bottom holes were obtained by using single-cone bits with different offset distances of $0,3.2,5.8$ and $9.0 \mathrm{~mm}$, respectively, in bench tests (as shown in Fig. 7). After crushed or cut by single-cone bits with different offset distances, there were different track patternson on the rock surface. The probability that broken rock was crushed again by the teeth decreased with increase of offset distance, thus improving the rock-breaking efficiency. The teeth track shows that the rock-breaking mechanism of the offset single-cone bit was a scraping action. This indicates that the offset single-cone bit was a chipping type bit.

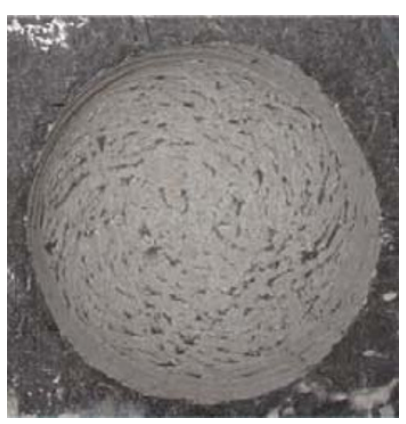

(a) $d=0$

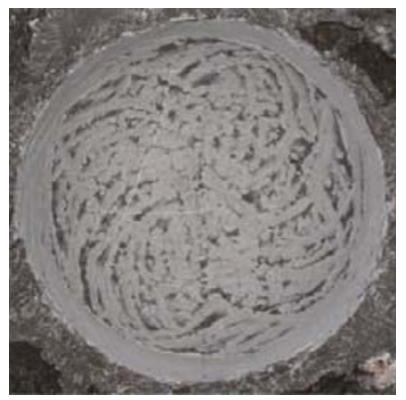

(c) $d=5.8 \mathrm{~mm}$

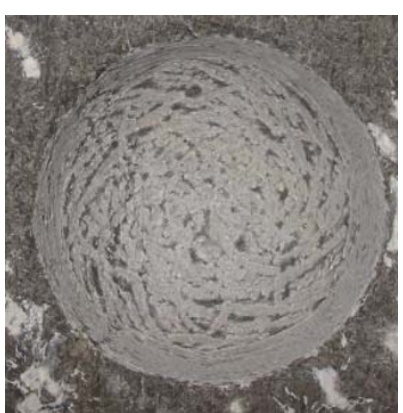

(b) $d=3.2 \mathrm{~mm}$

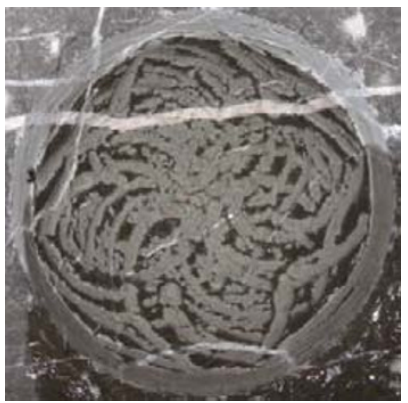

(d) $d=9.0 \mathrm{~mm}$
Fig. 7 Pictures of bottom hole crushed by single-cone bits with different offset distances

\section{Conclusions}

1) For single-cone bits with different offset distances, the transmission ratio changed slightly with rotary speed of bit and weight on bit. The designers need not to consider the influence of offset distance when designing the cutting structure of single-cone bit.

2) The rate of penetration of the offset single-cone bit increased with increase of WOB and offset distance. Designers could increase offset distance properly in order to increase ROP when designing the bit.

3) The torque on bit increased with increase of offset distance under the same experimental conditions, so the influence of torque on bit on the strength of drilling pipe should be considered.

4) The bottom holes drilled with single-cone bits with different offset distances had different track patterns. The probability that broken rock was crushed again by teeth decreased with increase of offset distance, thus increasing rate of penetration and drilling efficiency.

\section{References}

Deng R, Wang F and Xiong C W. Design and analysis of mono-cone bit. Journal of Sichuan University (Engineering Science Edition). 2001. 33(5): 51-54 (in Chinese)

Fletcher S. Custom designed single-cone bit works for well off Albania. Oil \& Gas Journal. 2003. 101(30): 44-45

Langford Jr J W. One-cone bits improve efficiency of drilling small diameter holes. Petroleum Engineer International. 1999. 72(2): 23-28

Li J B and Tan A P. The slim hole technology and problems in re-entry in Zhongyuan Oilfield. Drilling \& Production Technology. 2000. 23(1): 9-13 (in Chinese)

Ma H W, Deng R and Sheng Y P. The well-bottom trace analysis of onecone bit. Oil Field Equipment. 2004. 33(5): $41-43$ (in Chinese)

Moran D P and Witman G B. One cone bit with interchangeable cutting structures, a box-end connection, and integral sensory devices. US Patent. 6814162. 2004

Qiu Z J. New technology promotes the discovery of the Tarim Natural Gas Province. Engineering Science. 2000. 2(9): 38-41 (in Chinese)

Witman G B, Wilson P, McDonough S D, et al. Single cone rock bit having inserts adapted to maintain hole gage during drilling. US Patent. 7100711. 2006

Wu X G and Liu C. Approaches to improvement of ROP in slim holes. Petroleum Drilling Techniques. 2000. 28(1): 17-19 (in Chinese)

Xia Y W, Yang G Q, Li S T, et al. Emulation model of one-cone bit drilling at well bottom. Underground Space. 2002. 22(1): 33-37 (in Chinese)

Yu K A, Deng R and Yang S L. The application prospects of mono-cone bits. China Petroleum Machinery. 1994. 22(5): $49-51$ (in Chinese)

Yu K A, Deng R and Yang S L. Test and analysis of transmission ratio of mono-cone bits. China Petroleum Machinery. 1995. 23(6): 14-17 (in Chinese)

$\mathrm{Yu} \mathrm{K} \mathrm{A}$ and $\mathrm{Yu} \mathrm{L}$. The research on the rock-disintegrating track of an offset mono-cone bit. Oil Field Equipment. 2007. 36(1): 5-9 (in Chinese)

(Edited by Sun Yanhua) 